\title{
AMBIENT TO HIGH-TEMPERATURE FRACTURE TOUGHNESS AND CYCLIC FATIGUE BEHAVIOR IN ALCONTAINING SILICON CARBIDE CERAMICS
}

\author{
R. Yuan, J. J. Kruzic, X. F. Zhang, L. C. De Jonghe, and R. O. Ritchie \\ Materials Sciences Division, Lawrence Berkeley National Laboratory \\ and \\ Department of Materials Science and Engineering, \\ University of California, Berkeley, CA 94720, USA
}

August, 2003

submitted to

Acta Materialia

Work supported by the Director, Office of Science, Office of Basic Energy Sciences, Division of Materials Sciences and Engineering of the U.S. Department of Energy under Contract No. DE-AC03-76SF00098. 


\title{
Ambient to High-Temperature Fracture Toughness and Cyclic Fatigue Behavior in Al-Containing Silicon Carbide Ceramics
}

\author{
R. Yuan, J. J. Kruzic, X. F. Zhang, L. C. De Jonghe, and R. O. Ritchie \\ Materials Sciences Division, Lawrence Berkeley National Laboratory, and \\ Department of Materials Science and Engineering, \\ University of California, Berkeley, CA 94720, USA
}

\begin{abstract}
A series of in situ toughened, Al, B and C containing, silicon carbide ceramics $(\mathrm{ABC}-\mathrm{SiC})$ has been examined with $\mathrm{Al}$ contents varying from 3 to $7 \mathrm{wt} \%$. With increasing $\mathrm{Al}$ additions, the grain morphology in the as-processed microstructures varied from elongated to bimodal to equiaxed, with a change in the nature of the grain-boundary film from amorphous to partially crystalline to fully crystalline. Fracture toughness and cyclic fatigue tests on these microstructures revealed that although the $7 \mathrm{wt} \% \mathrm{Al}$ containing material (7ABC) was extremely brittle, the 3 and particularly 5 wt.\% $\mathrm{Al}$ materials (3ABC and 5ABC, respectively) displayed excellent crack-growth resistance at both ambient $\left(25^{\circ} \mathrm{C}\right)$ and elevated $\left(1300^{\circ} \mathrm{C}\right)$ temperatures. Indeed, no evidence of creep damage, in the form of grain-boundary cavitation, was seen at temperatures at $1300^{\circ} \mathrm{C}$ or below. The enhanced toughness of the higher Al-containing materials was associated with extensive crack bridging from both interlocking grains (in 3ABC) and uncracked ligaments (in 5 $\mathrm{ABC}$ ); in contrast, the $7 \mathrm{ABC} \mathrm{SiC}$ showed no such bridging, concomitant with a marked reduction in the volume fraction of elongated grains. Mechanistically, cyclic fatigue-crack growth in $3 \mathrm{ABC}$ and $5 \mathrm{ABC} \mathrm{SiC}$ involved the progressive degradation of such bridging ligaments in the crack wake, with the difference in the degree of elastic vs. frictional bridging affecting the slope, i.e., Paris law exponent, of the crack-growth curve.
\end{abstract}

Keywords: Ceramics; Structural SiC; Mechanical properties (fracture toughness, fatigue); Grain bridging; Uncracked ligaments 


\section{Introduction}

Silicon carbide $(\mathrm{SiC})$ ceramics represent a class of materials that may potentially replace Ni-base superalloys as higher temperature engine materials because of their high strength, low density and superior oxidation/creep resistance above $1100^{\circ} \mathrm{C}$. However, one principal factor which limits their application is their low fracture toughness, which in commercial material is typically on the order of 2-3 MPa $\sqrt{\mathrm{m}}$. In light of this, much recent research on $\mathrm{SiC}$ [1-11] has focused on ways to increase this toughness. Of these, the approach of in situ toughening with aluminum, boron and carbon additions to produce so-called ABC-SiC [3] has been particularly successful in increasing the ambienttemperature fracture toughness to above $9 \mathrm{MPa} \sqrt{\mathrm{m}}$ [7], which is the highest toughness ever reported for SiC. This was achieved in a $3 \mathrm{wt} . \%$ Al-containing material (3ABC-SiC) by developing a microstructure of interlocking, high aspect-ratio grains, separated by grain boundaries weakened by the presence of a thin intergranular glassy film; this in turn induced intergranular fracture and consequent extrinsic toughening ${ }^{1}$ from the bridging of interlocking grains in the crack wake [7]. However, under cyclic loads, 3ABC-SiC was found to be susceptible to fatigue-crack growth, due to a cyclic-loading induced degradation in the zone of grain bridging in the crack wake $[7,8]$.

Subsequent work on $3 \mathrm{ABC}-\mathrm{SiC}$ at elevated temperatures [9-11,13] revealed that the fracture toughness and fatigue-crack growth properties were only marginally decreased at temperatures up to $1300^{\circ} \mathrm{C}$, with no apparent change in cracking and shielding mechanisms; furthermore, little or no evidence of creep damage, in the form of grainboundary cavitation, could be detected at temperatures below $1350^{\circ} \mathrm{C}$ [13]. This excellent combination of low-temperature toughness and high-temperature toughness/creep behavior was found to be the result of a remarkable property of $3 \mathrm{ABC}$ $\mathrm{SiC}$, that of the in situ crystallization of the intergranular glassy films at temperatures above $\sim 1100^{\circ} \mathrm{C}[9-11,13,14]$. Moreover, although the grain-boundary films remain

\footnotetext{
${ }^{1}$ Extrinsic toughening involves micro-mechanisms, such as crack bridging or microcracking, which act primarily in the crack wake to locally "shield" the crack from the applied (global) driving force; they therefore enhance the crack-growth toughness and invariably result in resistance-curve behavior. They are to be compared with intrinsic mechanisms which operate ahead of the crack tip to enhance the inherent toughness of the material; these mechanisms mainly promote resistance to crack initiation [12].
} 
crystalline, the high toughness was retained, indeed increased, on subsequently cooling to room temperature [10].

Accordingly, from the prospective of developing SiC with such optimized properties, two means of controlling microstructures in ABC-SiC can be contemplated. The first of these is to anneal the material (e.g., at $1300^{\circ} \mathrm{C}$ ) prior to use to cause the crystallization of the amorphous grain-boundary films. Chen et al. [9-11] found that in addition to conferring good high-temperature creep and fatigue resistance, such heat treatments led to a $\sim 20 \%$ increase in the room-temperature fracture toughness and fatigue-crack growth resistance (with no change in mechanism), compared to that in the as-hot-pressed material. However, an alternative approach is via microstructure modification through compositional changes, specifically by varying the aluminum content [15]. To date, several $\mathrm{ABC}-\mathrm{SiC}$ materials have been processed with aluminum contents between 3 and $7 \mathrm{wt} . \%$, where the changing $\mathrm{Al}$ additions resulted in significantly altered microstructures $[7-11,15]$. Whereas the $3 \mathrm{wt} . \%$ material (3ABC) develops a microstructure of relatively uniform elongated grains with amorphous grain-boundary films (as noted above), a bimodal distribution of both elongated and equiaxed grains with partially crystallized grain-boundary films is seen in the $5 \mathrm{ABC}$ material, compared to principally equiaxed grains with only a few elongated (needle-like) grains, all with fully crystallized grain boundaries, in the 7ABC-SiC.

The focus of the present work is to present a detailed examination of the fracture toughness and fatigue properties of three $\mathrm{ABC}-\mathrm{SiC}$ microstructures at ambient to elevated temperatures $\left(25^{\circ}\right.$ to $\left.1300^{\circ} \mathrm{C}\right)$, with the objective of defining the salient damage and toughening mechanisms and their relationship to the characteristic microstructures involved.

\section{Experimental Procedures}

\section{(1) Processing of $A B C-S i C$}

Submicron $\beta$-SiC powder (Betarundum, Grade ultrafine, IBIDEN, Japan), with a mean particle size of $0.27 \mu \mathrm{m}$, was mixed with $\mathrm{Al}, \mathrm{B}$ and $\mathrm{C}$ additives in toluene. The $\mathrm{Al}$ powder (H-3, Valimet, Stockton, CA), which had an average size of $3 \mu \mathrm{m}$, was added in amounts of 3, 5 and 7 wt.\%, whereas the boron (Callery Chemical, Callery, PA) was kept 
constant at 0.6 wt. $\%$. The carbon was introduced as 4 wt.\% Apiezon wax, which on pyrolysis yielded $\sim 2$ wt.\% C content. The slurry was ultrasonically agitated, stir-dried and sieved through a 200 mesh screen. After cold die compression at $35 \mathrm{MPa}$, the green compacts were hot-pressed at $1900^{\circ} \mathrm{C}$ for $1 \mathrm{~h}$ at $50 \mathrm{MPa}$ pressure in graphite dies lined with graphite foil, under a constant gaseous argon flow at $7 \mathrm{kPa}$, to produce $\sim 4 \mathrm{~mm}$ thick, $38 \mathrm{~mm}$ diameter disks. Unless noted, all results presented are from samples tested in the as-processed state; however, for a few room temperature experiments specimens were tested after $\sim 72 \mathrm{~h}$ at $1300^{\circ} \mathrm{C}$ in flowing argon, to see if prolonged exposure to elevated temperatures affects the room temperature properties.

\section{(2) Microstructure Characterization}

After diamond grinding $\sim 500 \mu \mathrm{m}$ off each surface, both sides of the hot-pressed pellets were polished to a $1 \mu \mathrm{m}$ finish. Densities of the hot-pressed specimens were determined by Archimedes' method and found to be greater than $99 \%$ of theoretical density for all samples.

$\mathrm{X}$-ray diffraction (XRD) was carried out on the polished surfaces of the disks over the range from $20^{\circ}$ to $80^{\circ}(2 \theta)$ at steps of $0.05^{\circ}$, with a time constant of $1 \mathrm{~s}$. Quantitative analysis of the $\mathrm{SiC}$ polytypes for each microstructure was carried out using the X-ray peak intensities by considering the four most common polytypes, $3 \mathrm{C}, 4 \mathrm{H}, 6 \mathrm{H}$, and $15 \mathrm{R}$, using the system of equations derived by Ruska et al; details of this method may be found in Ref. [16].

Grain morphology was observed using field-emission scanning electron microscopy (SEM) (secondary electron mode) of both polished and plasma etched specimens. Highresolution transmission electron microscopy (HRTEM) was performed to examine the nature of the grain boundaries using $3 \mathrm{~mm}$ diameter disks which were sliced from bulk SiC. After mechanical grinding and polishing down to $100 \mu \mathrm{m}$ thick, the central area of each disk was dimpled to $10 \mu \mathrm{m}$ thick, and then argon ion milled to make the samples electron transparent. Microstructural characterization was performed in a $200 \mathrm{kV}$ fieldemission-gun Philips CM200 transmission electron microscope, equipped with an energy-dispersive X-ray spectroscopy (EDS) system for chemical microanalysis.

\section{(3) Fracture and Fatigue Testing}


Resistance curves (R-curves) and fracture toughness $K_{\mathrm{c}}$ values were determined using fatigue precracked, $3 \mathrm{~mm}$ thick, disk-shaped compact-tension DC(T) samples (with a width of $W=28 \mathrm{~mm}$ ), in general accordance with ASTM Standard E-399. The notch depth was $\sim 9 \mathrm{~mm}(\sim 0.3 \mathrm{~W})$, such that crack sizes, $a$, after precracking were typically 11 to $17 \mathrm{~mm}$ in length. Precracking was performed at ambient temperature by cyclic fatigue loading the $\mathrm{DC}(\mathrm{T})$ specimens, which contained half-chevron notches; procedures are described in ref. [17]. Prior to R-curve testing, precracked specimens were additionally cycled for $\sim 24 \mathrm{hr}$ at a stress-intensity range just below the $\Delta K_{\text {th }}$ fatigue threshold in an attempt to minimize the presence of bridging ligaments in the crack wake; no further crack extension was detected by compliance techniques or optical microscopy during this period. For $7 \mathrm{ABC}$ samples, fatigue precracking was not possible due to the inherent brittleness of this microstructure. Accordingly, to get an upper bound for the toughness, fracture toughness tests were conducted using "razor micronotched" samples with a root radius of $\sim 20 \mu \mathrm{m}$ instead of an atomically sharp precrack. Micronotches were produced by repeatedly rubbing a razor blade over the tip of a straight saw-cut notch in the presence of a $1 \mu \mathrm{m}$ diamond slurry.

At ambient temperatures, R-curves were determined to evaluate the toughness of the $3 \mathrm{ABC}$ and $5 \mathrm{ABC}$ microstructures; however at elevated temperatures, due to the difficulty of conducting such tests at $1300^{\circ} \mathrm{C}$, single-value fracture toughness values were obtained by computing $K_{\mathrm{c}}$ from the peak load at fracture using standard stress-intensity solutions [18]. Ambient-temperature tests were conducted in controlled room air $\left(25^{\circ} \mathrm{C}, \sim 45 \%\right.$ relative humidity), whereas all testing at higher temperatures was carried out in flowing argon gas at atmospheric pressure in an environmental chamber/furnace with graphite elements, which maintained the specified temperature to within $\pm 1^{\circ} \mathrm{C}$.

Cyclic fatigue-crack growth testing was also performed at $25^{\circ}$ and $1300^{\circ} \mathrm{C}$ in identical environments using similar-sized DC(T) specimens, in general accordance with ASTM Standard E-647, modified for brittle materials using procedures outlined in ref. [17]. Samples for testing at both low and high temperatures were initially fatigue precracked at ambient temperature, as described above. All testing was performed on computercontrolled MTS servo-hydraulic testing machines, operating at a test frequency of $25 \mathrm{~Hz}$ (sinusoidal waveform) and a tension-tension load ratio (ratio of minimum to maximum 
loads) of $R=0.1$. Fatigue-crack growth rates, $d a / d N$, were determined under stressintensity $K$ control over five decades of growth rates from threshold to instability $\left(\sim 10^{-11}\right.$ to $10^{-6} \mathrm{~m} /$ cycle). The $\Delta K_{\text {th }}$ and $K_{\text {max,th }}$ fatigue thresholds, which were operationally defined at minimum growth rate of $10^{-10}-10^{-11} \mathrm{~m} /$ cycle, were approached under decreasing $K$ (load-shedding) conditions using a normalized $K$-gradient $(1 / K . d K / d a)$ of $0.1 \mathrm{~mm}^{-1}$.

For both toughness and fatigue-crack growth tests, crack lengths were monitored at ambient temperatures using back-face strain, elastic unloading compliance methods [19]. Measurements were made with a $350 \Omega$ strain gauge (1.92 $\mathrm{mm}$ gauge length), affixed to the center of the back face of the test samples, using the numerical compliance relationship between crack length and back-face strain for the $\mathrm{DC}(\mathrm{T})$ specimen taken from ref. [20]. Crack lengths were continuously monitored in situ and recorded at $25 \mu \mathrm{m}$ increments; corresponding growth rates were computed by averaging over crack extensions of $100 \mu \mathrm{m}$.

Corresponding crack length measurements at elevated temperatures were carried out using a direct-current electrical-potential drop method [9,21], which was made possible by the fact that there is a significant decrease in electrical resistivity $\rho$ of silicon carbide above $600^{\circ} \mathrm{C}(\rho \sim 10 \Omega \mathrm{m})$. This approach involves passing a constant current through the $\mathrm{DC}(\mathrm{T})$ specimen and measuring the potential developed across the notch, using a relationship between voltage and crack length determined both numerically and experimentally in Ref. [20] for the DC(T) geometry. A constant direct current of $\sim 400$ $800 \mathrm{~mA}$ was used so that the initial output potential was $0.4 \mathrm{~V}$. Full details are given in refs. $[9,21]$.

Due to crack bridging, errors were invariably incurred in the compliance and potential crack-length measurements; accordingly, verification of the crack length was achieved via optical microscopy. For elevated temperature tests, samples were periodically cooled down to ambient temperature to verify the crack size. Discrepancies between the compliance/electrical-potential and optically measured crack length were corrected by assuming that the error accumulated linearly with crack extension.

\section{(4) Fractography}


Fracture surfaces and corresponding crack paths for cracks grown under both monotonic and cyclic loads were examined in the SEM in the secondary electron mode. The crack paths were used to examine how the crack interacted with the salient features of the microstructure, and were obtained by metallographically polishing sections taken perpendicular to the crack surface. Additionally, the damage regions around the crack tip after fatigue cycling were examined using TEM, with specimens prepared as described above, using special care to ensure that the crack tips were in the thinnest, electron transparent, region.

\section{(5) Crack-Opening Profile Measurements}

To assess the differences in grain bridging, crack-opening profile measurements were made by in situ loading one $3 \mathrm{ABC}$ and one $5 \mathrm{ABC}$ sample with almost identical crack lengths in the field-emission SEM, after R-curve measurements had been made. Each sample was loaded to an applied driving force of $6.2 \mathrm{MPa} \vee \mathrm{m}$, corresponding to $\sim 82 \%$ of the driving force need for crack extension in the $3 \mathrm{ABC}$ material (i.e., peak toughness). Measurements of the full crack opening, $2 u$, were made at a resolution of $10 \mathrm{~nm}$ at magnifications of up to $30,000 \mathrm{X}$ near the crack tip. The crack lengths were also measured in situ to be sure crack extension did not occur during loading. Readings were made at $\sim 50 \mu \mathrm{m}$ increments to give an adequate number of data points to get a reasonable estimate of the average crack-opening behavior.

\section{Results}

\section{(1) Microstructure Features}

Phase and grain morphology: Three quite distinct microstructures were obtained after hot pressing $\mathrm{ABC}-\mathrm{SiC}$ with the different $\mathrm{Al}$ contents of nominally 3, 5 and 7 wt.\% (Fig. 1). In $3 \mathrm{ABC}-\mathrm{SiC}$, elongated grains corresponding to the hexagonal $4 \mathrm{H}$ or $6 \mathrm{H} \alpha-\mathrm{SiC}$ phases were most prevalent (Fig. 1a). Their size and shape were relatively uniform, with lengths and widths of, respectively, $l \sim 4$ to $7 \mu \mathrm{m}$ and $w \sim 1-2 \mu \mathrm{m}$, and an aspect ratio of

$\sim 5$. Submicron, equiaxed $\mathrm{SiC}$ grains corresponding to cubic $3 \mathrm{C} \beta$-SiC phase were also observed. 
Increasing nominal $\mathrm{Al}$ content to $5 \mathrm{wt} . \%$ caused marked microstructural changes, with a bimodal structure being formed comprising a significant volume fraction of both elongated and equiaxed $\mathrm{SiC}$ grains (Fig. 1b). The higher $\mathrm{Al}$ additions in 5ABC-SiC apparently promoted anisotropic growth of the elongated grains, resulting in an aspect ratio of $\sim 23$, almost five times that of $3 \mathrm{ABC}-\mathrm{SiC}$.

This trend was continued with additional increases in $\mathrm{Al}$ content. In 7ABC-SiC, the aspect ratio of the elongated $\alpha-\mathrm{SiC}$ grains was further increased to $\sim 32$; however, the proportion of such grains was significantly reduced with the submicron equiaxed $\beta-\mathrm{SiC}$ grains becoming predominant (Fig. 1c). Detailed microstructural characteristics for the three microstructures from Ref. [15] are summarized in Table 1.

Grain boundaries: In addition to the differing phase and grain morphology, the other major distinction in the three microstructures was in the nature of the grain boundaries. During the liquid-phase sintering, nanoscale intergranular films are typically formed between SiC grains. As reported previously [14], TEM studies revealed that the intergranular films in as-processed $3 \mathrm{ABC}-\mathrm{SiC}$ were amorphous (Fig. 2) with an Al-rich composition, as determined by EDS analysis. With increasing Al content, segregation of the $\mathrm{Al}$ atoms to the intergranular films was found to be increased by $32 \%$ and appeared to be saturated and constant for both $5 \mathrm{ABC}$ and $7 \mathrm{ABC}$, although considerable amounts of free $\mathrm{Al}$ were detected in the latter structure.

With respect to the structure of the boundaries, whereas the intergranular films were fully amorphous in $3 \mathrm{ABC}$ and fully crystalline in $7 \mathrm{ABC}$, both amorphous and crystalline films were frequently observed in $5 \mathrm{ABC}$ (Fig. 2). It should be noted that epitaxial crystalline grain-boundary films were often formed on the (0001) grain-boundary surface of the matrix $\alpha-\mathrm{SiC}$ grains. This epitaxial growth is attributed to the fact that one of the identified phases for the crystalline films was $2 \mathrm{H}$-wurtzite, which is similar in structure to the $4 \mathrm{H}$ - or $6 \mathrm{H}-\mathrm{SiC}$ matrix grains [14]. Because of this epitaxial growth, crystalline grainboundary films are not always easily seen in high-resolution TEM images like the ones shown in Fig. 2; however, the consistent detection of two to three monolayers of Al segregation in the boundaries was reliably used to confirm the existence of these films. 
The microstructures of the samples subjected to $72 \mathrm{hr}$ exposures at $1300^{\circ} \mathrm{C}$ were essentially identical to those of as-hot-pressed conditions, except that the grain boundaries were all crystallized in 3,5 and 7ABC.

\section{(2) Fracture Toughness and Strength}

Fracture Toughness: The variation in fracture toughness at $25^{\circ}$ and $1300^{\circ} \mathrm{C}$ with $\mathrm{Al}$ wt.\% is summarized in Table 2. For both as-hot-pressed and annealed 3ABC and 5ABC structures at $25^{\circ} \mathrm{C}$, R-curves were determined and are shown in Fig. 3. Peak values from the R-curves indicate that in as-hot-pressed condition, $5 \mathrm{ABC}$ is some $17 \%$ tougher than $3 \mathrm{ABC}$; both these structures are essentially twice as tough as $7 \mathrm{ABC}$, which displayed a fracture toughness $K_{\mathrm{c}}$ value no greater than $4.0 \mathrm{MPa} \sqrt{\mathrm{m}}$, comparable to that of commercial $\mathrm{SiC}$ (e.g., Hexaloy $\mathrm{SA}$ ). Results for $3 \mathrm{ABC}$ and $5 \mathrm{ABC}$ at elevated temperatures showed a reduction in the fracture toughness at $1300^{\circ} \mathrm{C}$ of roughly 20 to $40 \%$, while $7 \mathrm{ABC}$ had an $\sim 20 \%$ increase. Finally, experiments using samples preexposed for $72 \mathrm{hr}$ at $1300^{\circ} \mathrm{C}$ prior to room temperature testing showed that although grain-boundary crystallization occurred, there was no significant effect on the toughness (Table 2); the toughness of $3 \mathrm{ABC}$ and $5 \mathrm{ABC}$ showed a $16 \%$ increase and $26 \%$ decrease, respectively.

Strength: For comparison, ambient temperature four-point bend strength results from Ref. [15] for all three of the as-hot-pressed ABC-SiCs are given in Table 2 where each value represents the average of five measurements along with the standard deviation. All three microstructures displayed strengths near or in excess of $\sim 500 \mathrm{MPa}$. $3 \mathrm{ABC}$ had a 30 to $40 \%$ higher bend strength than either the $5 \mathrm{ABC}$ and $7 \mathrm{ABC}$ structures, which showed comparable strength levels.

\section{(3) Fatigue-Crack Growth Behavior}

The variation in fatigue-crack growth rates, $d a / d N$, with applied stress-intensity range, $\Delta K$, for $3 \mathrm{ABC}-5 \mathrm{ABC}$ - and $7 \mathrm{ABC}-\mathrm{SiC}$ at $25^{\circ}$ and $1300^{\circ} \mathrm{C}$ is shown in Fig. 4 . The $d a / d N$ vs. $\Delta K$ data were fit to a simple Paris power-law formulation:

$$
d a / d N=C^{\prime} \Delta K^{m},
$$


where $C^{\prime}$ and $m$ are scaling constants. Values of these constants, together with a summary of the fatigue threshold data, are listed in Table 3. All curves show very high Paris-law exponents $(m>40)$, which are typical of brittle materials, and have $K_{\max , \text { th }}$ thresholds that approach $80 \sim 90 \%$ of the fracture toughness, $K_{\mathrm{c}}$ (with the exception of $7 \mathrm{ABC}$ ). It should be noted that the Paris-law exponent for $5 \mathrm{ABC}$ is about twice that for $3 \mathrm{ABC}$, which suggests a difference in fatigue mechanism (as discussed below).

It is apparent that fatigue-crack growth resistance scales with the fracture toughness in SiC. Considering first the ambient-temperature results, the $5 \mathrm{ABC}$ structure, with a $K_{\max \text {,th }}$ threshold of 7.9 MPa $\sqrt{\mathrm{m}}$, displayed the best properties followed by $3 \mathrm{ABC}$, where $K_{\max , \text { th }}$ $\sim 5.9 \mathrm{MPa} \sqrt{\mathrm{m}}$. The $7 \mathrm{ABC}$ structure was so brittle that it simply failed catastrophically when the ambient temperature fracture toughness was reached, i.e., when $K_{\max }=K_{\mathrm{c}} \sim 3-$ $4 \mathrm{MPa} \sqrt{ }$; this structure showed no susceptibility to fatigue failure. With increasing temperature from $25^{\circ}$ to $1300^{\circ} \mathrm{C}$, fatigue thresholds were reduced for $3 \mathrm{ABC}$ and $5 \mathrm{ABC}$, reflecting the lower toughnesses at high temperature; however, the Paris-law exponents were very similar to their room temperature values, which is indicative of similar damage mechanisms being active at low and high temperatures.

\section{(4) Fractography and Crack Paths}

Overload fracture surfaces from the fracture toughness samples show a transition of increasing transgranular fracture with increasing $\mathrm{Al}$ content from 3 to 7 wt.\% (Fig. 5); however, even for $7 \mathrm{ABC}$ there is still some intergranular fracture between the fine grains. SEM micrographs of the crack-path trajectories in Fig. 6a confirms the intergranular fracture mode in $3 \mathrm{ABC}$, and provides evidence that crack-tip shielding by individual grain bridging (frictional bridging) in the crack wake is the primary toughening mechanism in this structure, as reported in refs. [7-11]. This mechanism of grain bridging pertains to behavior in $3 \mathrm{ABC}$ at both the low and high temperatures (Fig. 6b). Crack bridging is also apparent in the $5 \mathrm{ABC}$ structure at both $25^{\circ}$ and $1300^{\circ} \mathrm{C}$; however, the primary mechanism is quite different (Fig. 6c-f). Here, the majority of bridges are composed of uncracked ligaments of $\mathrm{SiC}$ which span the crack wake. Uncrackedligament bridging is a toughening mechanism observed in many materials, including metal-matrix composites [22], $\gamma$-based TiAl intermetallics [23], and even human bone 
[24]. Such ligaments were typically composed of one or more elongated grains; indeed, the crack path in both the $3 \mathrm{ABC}$ and $5 \mathrm{ABC}$ microstructures appeared to preferentially seek out these $\alpha$-SiC grains. In contrast, the crack path in the as-processed $7 \mathrm{ABC}$ microstructure is predominantly transgranular through both the equiaxed and elongated grains, with no evidence of any form of bridging.

Corresponding fatigue fracture surfaces for the $3 \mathrm{ABC}$ and $5 \mathrm{ABC}$ structures were essentially identical to the overload fracture surfaces, except for the presence of debris. Such observations are consistent with the generally accepted mechanisms for the fatigue of grain-bridging ceramics, involving (i) damage (crack-advance) mechanisms ahead of the crack tip essentially identical to those under monotonic (non-cyclic) loading, and (ii) the progressive degradation of grain bridging with cyclic loading behind the crack tip, associated with such processes as frictional wear in the sliding grain boundaries and the cracking/crushing of crack-surface asperities $[7,25,26]$.

As noted above, fracture surfaces and crack paths at $1300^{\circ} \mathrm{C}$ are of similar nature to that at room temperatures, with clear evidence of grain bridging and no evidence of creep damage in the form of softening of the intergranular films and resulting grain-boundary cavitation. This is apparent from high magnification TEM images of the crack-tip regions in $3 \mathrm{ABC}$ and $5 \mathrm{ABC}$ after fatigue-crack growth at high temperatures (Fig. 7). Indeed, based on the fractographic characterization and the results presented in Figs. 6 and 7 , we can conclude that the mechanisms of fracture and fatigue-crack propagation in both these microstructures are essentially unchanged between $25^{\circ}$ and $1300^{\circ} \mathrm{C}$.

\section{(5) Crack-Opening Profile Results}

Clearly, both toughening and fatigue-crack growth in the $3 \mathrm{ABC}$ and $5 \mathrm{ABC}$ structures are markedly influenced by the presence of crack bridging. In order to verify the existence of such crack-tip shielding, crack-opening profiles were measured for two cracks in samples used for R-curve testing, which were then loaded in situ in the fieldemission SEM to a stress intensity of $6.2 \mathrm{MPa} \vee \mathrm{m}$; results are shown in Fig. 8 and are compared with the computed crack-opening profile for an elastic traction-free crack at the same applied $K$. In this figure, it can be seen that measured crack openings are significantly smaller than that expected for a traction-free crack, clearly implying the 
presence of crack bridging in both samples. Furthermore, the crack in the $5 \mathrm{ABC}-\mathrm{SiC}$ sample has a smaller opening than that for the $3 \mathrm{ABC}-\mathrm{SiC}$ sample, indicative of more potent bridging in the $5 \mathrm{ABC}$ microstructure.

These differences in the degree of crack bridging can be quantified by fitting the neartip crack-opening profile to the Irwin crack-opening displacement solution for a linear elastic crack in order to obtain the near-tip stress intensity, $K_{\text {tip }}$ :

$$
u_{t o t}(x)=\frac{K_{t i p}}{E^{\prime}} \sqrt{\frac{8(a-x)}{\pi}},
$$

where $E^{\prime}$ is Young's modulus ( $E$ in plane stress, $E /\left(1-v^{2}\right)$ in plane strain, where $v$ is Poisson's ratio), and $x$ is the position of interest with origin at the load line. Regressions of the crack-tip opening profile data for the first $70 \mu \mathrm{m}$ after the crack tip yield a value of $2.5 \mathrm{MPa} \sqrt{\mathrm{m}}$ for $3 \mathrm{ABC}$ and $1.6 \mathrm{MPa} \sqrt{\mathrm{m}}$ for $5 \mathrm{ABC}$. Accordingly, considering that $K_{\text {tip }}$ may be expressed as:

$$
K_{\text {tip }}=K_{\text {app }}-K_{\text {br }} \text {, }
$$

where $K_{\text {app }}$ is the applied stress intensity $(6.2 \mathrm{MPa} \sqrt{\mathrm{m}})$ and $K_{\text {br }}$ is the contribution due to bridging, $K_{\mathrm{br}}$ is determined to be $3.7 \mathrm{MPa} \sqrt{\mathrm{m}}$ for $3 \mathrm{ABC}$ and $4.6 \mathrm{MPa} \sqrt{\mathrm{m}}$ for $5 \mathrm{ABC}$. It should be noted that, at the same applied stress intensity, the $5 \mathrm{ABC}$ microstructure develops the higher contribution from bridging, and the lower driving force experienced at the crack tip.

\section{Discussion}

\section{(1) Toughening Mechanisms}

Characterization of the observed crack paths (Fig. 6) along with the crack opening profile measurements (Fig. 8) affirm that crack bridging is the primary toughening mechanism in $3 \mathrm{ABC}$ and $5 \mathrm{ABC}-\mathrm{SiC}$; in contrast, no bridging was observed in the asprocessed $7 \mathrm{ABC}$ microstructure which had the lowest fracture toughness, comparable to that of commercial silicon carbides. For $3 \mathrm{ABC}-\mathrm{SiC}$, frictional bridging appears to be dominant whereby bridging stresses are developed by the frictional resistance to pullout and mechanical interlocking of grains which interact across the crack wake, 
schematically shown in Fig. 9a. Such frictional grain bridging is a common toughening mechanism for a variety of ceramic materials which fracture intergranularly [7,27-30].

Conversely, observations of cracking in the $5 \mathrm{ABC}$ microstructure indicate a change in toughening mechanism to uncracked-ligament, or elastic, bridging; with this change in mechanism there is an associated increase in toughness. As seen in Fig. 6c,d,e, uncracked ligaments, often several grains in size, were observed to bridge the crack wake in the $5 \mathrm{ABC}$ microstructure; frictional bridges, such as those seen in $3 \mathrm{ABC}$ (Fig 6a,b), were far less common. Such ligaments apparently form as a result of local crack arrest at microstructural inhomogeneities, which leaves unfractured ligaments in the crack wake, due to either non-uniform advance of the crack front or crack nucleation ahead of the main crack tip; this phenomenon is illustrated in Fig 9b. However, it is currently unclear what causes the transition from predominantly frictional to uncracked-ligament bridging, although this change must be related to the notable differences in microstructure and to the grain-boundary film properties. Specifically, the dominant local arresting points responsible for the formation of such uncracked ligaments may be attributed to large elongated grains oriented favorable for local crack deflection, as illustrated in Fig. 9b, and/or to spatial variations in grain boundary strengths due to structure ${ }^{2}$ or chemistry differences. Since the crack path follows the elongated grains almost exclusively, the higher aspect ratio and smaller fraction of elongated grains in the $5 \mathrm{ABC}$, as compared to the $3 \mathrm{ABC}$, structure undoubtedly promotes larger off-angle deflections as the crack propagates along the boundary of the $\alpha-\mathrm{SiC}$ grains; thus, with the next $\alpha$ grain further away than in the $3 \mathrm{ABC} \mathrm{SiC}$, uncracked ligaments are more probable, as shown schematically in Fig. 9b. Uncracked-ligament bridges are expected to be more potent than frictional bridges in that they should be able to sustain higher loads before failing. This is consistent with the higher toughness and the higher deduced bridging stress intensity, $K_{\mathrm{br}}$, of the $5 \mathrm{ABC}$ structure (described above), both of which confirm the enhanced degree of bridging where uncracked ligaments predominate.

Finally, the behavior of 7ABC is illustrated in Fig. 9c. Here, unlike the $3 \mathrm{ABC}$ and $5 \mathrm{ABC}$ microstructures, the crack path is predominantly transgranular, and proceeds

\footnotetext{
${ }^{2}$ While amorphous and the $2 \mathrm{H}$-wurtzite crystalline phase has been positively identified for some boundaries, other boundary structures may also exist.
} 
through both the equiaxed $\beta$ and elongated $\alpha-\operatorname{SiC}$ grains, with very few cases of intergranular fracture. With such a cracking morphology, there was no evidence of any form of bridging.

The fracture toughness values for both $3 \mathrm{ABC}$ - and 5ABC-SiC are slightly lower at $1300^{\circ} \mathrm{C}$ than their corresponding room temperature values, which is in agreement with previous results on $3 \mathrm{ABC}-\mathrm{SiC}$ [9]. Such a drop in toughness may be related to changes in the residual stress state, either by the relaxation of thermal mismatch stresses which, along with mechanical interlocking, may contribute to the tractions acting on the frictional bridges $[28,31,32]$, or by altering the mismatch stresses in triple point junctions, which has been shown to affect the toughness of silicon nitride [33]. It should be noted that $3 \mathrm{ABC}-\mathrm{SiC}$, which has a larger proportion of frictional bridges, experiences a larger drop in toughness compared to $5 \mathrm{ABC}-\mathrm{SiC}$. Such a result is consistent with a reduction in thermal stresses affecting the frictional bridging tractions, suggesting that the former mechanism indeed plays a role here.

While exposure to $1300^{\circ} \mathrm{C}$ is known to affect the microstructure of $\mathrm{ABC}-\mathrm{SiCs}$, by the crystallization of amorphous grain boundaries, along with associated chemistry changes, and the formation of nano-precipitates within the SiC grains [14,34], only minor effects on the subsequent low-temperature toughness were evident. Thus, it may be concluded that although the crystalline boundaries have a very positive impact on the hightemperature creep resistance of $3 \mathrm{ABC}$ and $5 \mathrm{ABC}$ silicon carbides [13], either amorphous or crystalline boundaries are sufficiently brittle to give intergranular fracture and hence high toughness in these materials at lower temperatures (see also ref. [10]).

Finally, it should be noted that although the $5 \mathrm{ABC}$ microstructure has the highest toughness, it also has the lowest strength (Table 2). This inverse dependence of strength and toughness may be attributed to the fact that $5 \mathrm{ABC}-\mathrm{SiC}$ has a larger (elongated) grain size, and correspondingly is expected to have larger initial flaw sizes. Although 7ABC$\mathrm{SiC}$ has the lowest toughness, its strength is comparable to that of $5 \mathrm{ABC}-\mathrm{SiC}$, again from smaller initial flaw sizes due to the smaller grains. The $3 \mathrm{ABC}$ microstructure achieves its relatively high fracture toughness with the smallest grain size, and accordingly, has the highest strength of the three microstructures.

\section{(2) Cyclic Fatigue Mechanisms}


Since the fatigue of brittle materials such as $\mathrm{SiC}$ is invariably controlled by the progressive degradation under cyclic loading of the prevalent extrinsic toughening (crack-tip shielding) mechanisms, a sound strategy for improving resistance to fatiguecrack growth is by making the shielding mechanisms more resilient in the presence of such cyclic loads. In this regard, in addition to providing increased toughening, uncracked-ligament bridges are significantly less susceptible to fatigue damage during cyclic loading since the cycle-dependent interfacial wear mechanisms that occur to degrade frictional bridges [26] are not relevant. Instead of wear of the sliding boundaries, the degradation of the uncracked-ligament bridges must occur by a fracture process, presumably when a critical failure stress is reached, a mechanism that is likely to be cycle-independent. Indeed, a reduced susceptibility to cyclic fatigue was observed in $5 \mathrm{ABC}-\mathrm{SiC}$, which is toughened primarily by such ligament bridging, as reflected by the much higher Paris-law exponents (i.e., steeper $d a / d N-\Delta K$ curves) (Table 3). This was especial apparent at $1300^{\circ} \mathrm{C}$ where fatigue data was unattainable for the $5 \mathrm{ABC}$ microstructure over much of the range of crack-growth rates due to unstable fracture of the specimens.

Thus, by increasing the $\mathrm{Al}$ content in $\mathrm{ABC}-\mathrm{SiC}$ to $\sim 5 \mathrm{wt} . \%$, which leads to a microstructure of high aspect-ratio $\alpha$-SiC grains with both amorphous and crystalline grain-boundary films, which in turn causes a change in the predominant crack-tip shielding mechanism from frictional to uncracked-ligament bridging, optimal crackgrowth resistance at $25^{\circ}$ and $1300^{\circ} \mathrm{C}$ can be obtained under both monotonic and cyclic loading. Not only is the ligament bridging mechanism a more potent mode of toughening in $\mathrm{ABC}$ silicon carbides, but it also is more resistant to degradation under cyclic loading and thus leads to a reduced susceptibility to fatigue failure.

\section{Conclusions}

An experimental study has been made of the microstructural and mechanistic origins of the fracture toughness and fatigue-crack growth resistance of a series of Al-containing $\mathrm{ABC}$-silicon carbides at $25^{\circ}$ and $1300^{\circ} \mathrm{C}$, the following conclusions can be made: 
(1) Of the three silicon carbides examined here (3, 5, and 7ABC $\mathrm{SiC}), 5 \mathrm{ABC}-\mathrm{SiC}$ demonstrated the highest peak toughness of $8.9 \mathrm{MPa} \sqrt{\mathrm{m}}$ at $25^{\circ} \mathrm{C}$ and $7.1 \mathrm{MPa} \sqrt{\mathrm{m}}$ at $1300^{\circ} \mathrm{C}$. These high toughness values were attributed to crack-tip shielding, primarily from uncracked-ligament bridging in the crack wake. Corresponding toughening in 3ABC-SiC was primarily associated with frictional grain bridging; this structure displayed roughly $15 \%$ lower toughness. No bridging was detected in 7ABC microstructure, which accordingly exhibited the lowest toughness, comparable to that of commercial $\mathrm{SiC}$.

(2) Whereas the 7ABC structure was too brittle to be susceptible to fatigue, $3 \mathrm{ABC}$ and $5 \mathrm{ABC}$ exhibited cyclic fatigue-crack growth at stress intensities above a $K_{\max \text {,th }}$ threshold which was roughly $80-90 \%$ of the peak toughness.

(3) Fatigue-crack growth in $3 \mathrm{ABC}$ and $5 \mathrm{ABC}$ was associated the suppression of crack bridging in the crack wake. In general, the $5 \mathrm{ABC}$ microstructure was less susceptible to fatigue, as evidenced by its steeper $d a / d N-\Delta K$ curve. This was attributed to the higher resilience of uncracked-ligament bridging to degradation under cyclic loading, as compared to frictional grain bridging in $3 \mathrm{ABC}$.

(4) While both the fracture toughness values and fatigue thresholds for 3 and $5 \mathrm{ABC}-\mathrm{SiC}$ were found to be lower at $1300^{\circ} \mathrm{C}$, the mechanisms of toughening and fatigue-crack propagation were found to be the same as at $25^{\circ} \mathrm{C}$. No evidence of creep cavitation damage was detected during the fatigue testing at $1300^{\circ} \mathrm{C}$.

Acknowledgements: This work was supported by the Director, Office of Science, Office of Basic Energy Sciences, Division of Materials Sciences and Engineering of the U.S. Department of Energy under Contract No. DE-AC03-76SF00098. The authors thank Q. Yang and Dr. J. M. McNaney for help with the sample fabrication and mechanical testing, and Dr. R. M. Cannon for useful discussions. TEM characterization was made possible through the use of the National Center for Electron Microscopy at the Lawrence Berkeley National Laboratory. 


\section{References}

[1] Kim DH, Kim CH. J. Am. Ceram. Soc. 1990;73:1431.

[2] Mitchell Jr TD, De Jonghe LC, MoberlyChan WJ, Ritchie RO. J. Am. Ceram. Soc. 1995;78:97.

[3] Cao JJ, MoberlyChan WJ, De Jonghe LC, Gilbert CJ, Ritchie RO. J. Am. Ceram. Soc. 1996;79:461.

[4] Padture NP. J. Am. Ceram. Soc. 1994;77:519.

[5] Padture NP, Lawn BR. J. Am. Ceram. Soc. 1994;77:2518.

[6] Lee SK, Kim CH. J. Am. Ceram. Soc. 1994;77:1655.

[7] Gilbert CJ, Cao JJ, MoberlyChan WJ, De Jonghe LC, Ritchie RO. Acta Metall. Mater. 1996;44:3199.

[8] Gilbert CJ, Ritchie RO. Acta Mater. 1998;46:609.

[9] Chen D, Gilbert CJ, Zhang XF, Ritchie RO. Acta Mater. 2000;48:659.

[10] Chen D, Zhang XF, Ritchie RO. J. Am. Ceram. Soc. 2000;83:2079.

[11] Chen D, Sixta ME, Zhang XF, De Jonghe LC, Ritchie RO. 2000, 4599.

[12] Ritchie RO. Int. J. Fract. 1999;100:55.

[13] Sixta M, Zhang XF, De Jonghe LC. J. Am. Ceram. Soc. 2001;84:2022.

[14] Zhang XF, Sixta M, De Jonghe LC. J. Am. Ceram. Soc. 2000;83:2813.

[15] Zhang XF, Yang Q, De Jonghe LC. Acta Mater. 2003;51:3849.

[16] Ruska J, Gauckler LJ, Lorenz JL, Rexer HU. J. Mater. Sci. 1979;14:2013.

[17] Dauskardt RH, Ritchie RO. Closed Loop 1991;17:7.

[18] Murakami Y. Stress Intensity Factors Handbook. Pergamon Press, 1987. p. 640.

[19] Ritchie RO, Yu W. Small Fatigue Cracks. Ritchie RO, Lankford J, Ritchie RO,

Lankford JRitchie RO, Lankford Js. TMS-AIME, Warrendale, PA,1986, 167.

[20] Gilbert CJ, McNaney JM, Dauskardt RH, Ritchie RO. J. Test. Eval. 1994;22:117.

[21] Chen D, Gilbert CJ, Ritchie RO. J. Test. Eval. 2000;28:236.

[22] Shang JK, Ritchie RO. Metall. Trans. 1989;20A:897.

[23] Chan KS. Metall. Trans. 1993;24A:569.

[24] Nalla RK, Kinney JH, Ritchie RO. Nature Materials 2003;2:164.

[25] Gilbert CJ, Dauskardt RH, Ritchie RO. J. Am. Ceram. Soc. 1995;78:2291.

[26] Lathabai S, Rödel J, Lawn B. J. Am. Ceram. Soc. 1991;74:1348.

[27] Swanson PL, Fairbanks CJ, Lawn BR, Mai Y-W, Hockey BJ. J. Am. Ceram. Soc.

1987;70:279.

[28] Bennison SJ, Lawn BR. Acta Metall. 1989;37:2659.

[29] Mai Y-W, Lawn BR. J. Am. Ceram. Soc. 1987;70:289.

[30] Li C-W, Lee D-J, Lui S-C. J. Am. Ceram. Soc. 1992;75:1777.

[31] Swain MV. J. Mater. Sci. Lett. 1986;5:1313.

[32] Kokaly MT, Tran DK, Kobayashi AS, Dai X, Patel K, White KW. Mater. Sci. Eng. 2000;A285:151.

[33] Pezzotti G, Kleebe H-J. Journal of the European Ceramic Society 1999;19:451.

[34] Zhang XF, Sixta ME, Chen D, De Jonghe LC. J. Mater. Sci. 2001;36:5447. 
Table 1. Comparison of Microstructures of ABC-SiC (after Ref. [15])

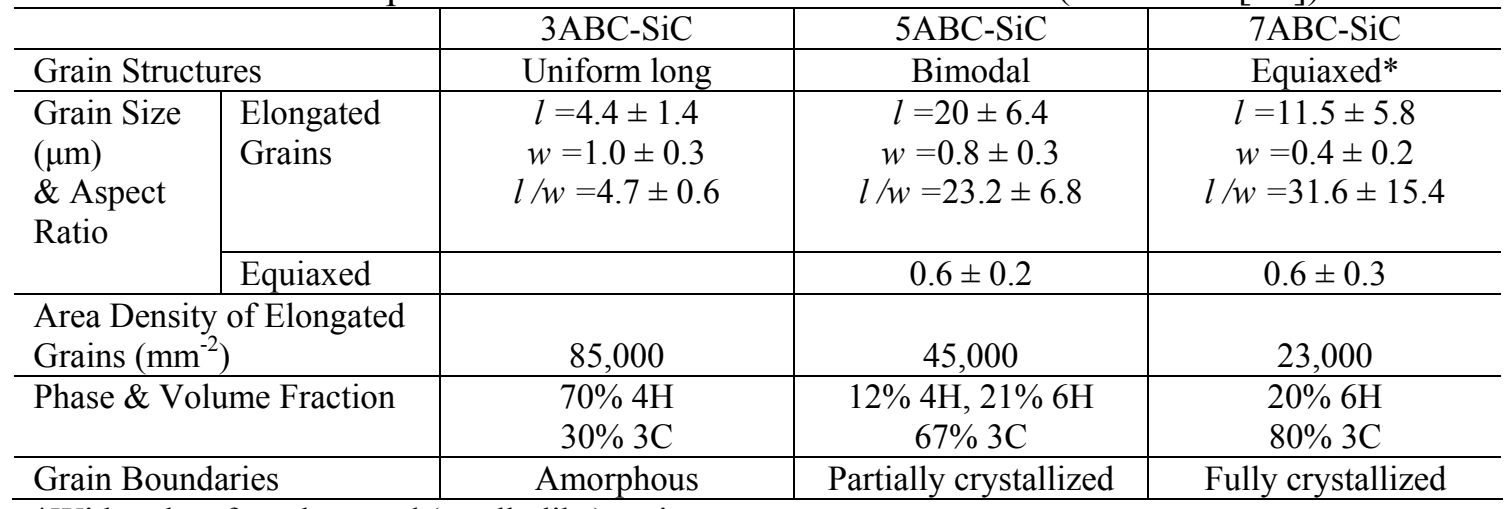

*With only a few elongated (needle-like) grains

Table 2. Comparison of Mechanical Properties of ABC-SiC

\begin{tabular}{l|c|c|c}
\hline & 3ABC-SiC & 5ABC-SiC & 7ABC-SiC \\
\hline $\begin{array}{l}\text { Strength at } 25^{\circ} \mathrm{C},(\text { Ref. [15]) } \\
\text { 4-pt bending }(\mathrm{MPa})\end{array}$ & $691 \pm 12$ & $480 \pm 30$ & $533 \pm 58$ \\
\hline $\begin{array}{l}\text { Toughness } K_{\mathrm{c}} \text { at } 25^{\circ} \mathrm{C} \\
(\mathrm{MPa} \sqrt{\mathrm{m}})\end{array}$ & 7.6 & 8.9 & $\begin{array}{c}4.0^{*} \\
\text { (upper bound) }\end{array}$ \\
\hline $\begin{array}{l}\text { Toughness } K_{\mathrm{c}} \text { at } 1300^{\circ} \mathrm{C} \\
(\mathrm{MPa} \sqrt{\mathrm{m}})\end{array}$ & 4.5 & 7.4 & $\begin{array}{c}4.9^{*} \\
\text { (upper bound) }\end{array}$ \\
\hline $\begin{array}{l}\text { Toughness } K_{\mathrm{c}} \text { of pre-exposed } \\
\text { samples at } 25^{\circ} \mathrm{C}(\mathrm{MPa} \sqrt{\mathrm{m}})\end{array}$ & 8.8 & 6.6 & - \\
\hline
\end{tabular}

*Toughness evaluated from a razor micro-notch.

Table 3. Cyclic fatigue-crack growth properties for $\mathrm{ABC}-\mathrm{SiC}$ tested at $R=0.1, \nu=25 \mathrm{~Hz}$

\begin{tabular}{|c|c|c|c|c|c|c|c|}
\hline & \multirow{2}{*}{$\begin{array}{c}\text { Testing } \\
\text { Temperature } \\
\left({ }^{\circ} \mathrm{C}\right)\end{array}$} & \multicolumn{2}{|c|}{ Fatigue Thresholds } & \multirow{2}{*}{$\begin{array}{c}\text { Critical } \\
\text { Toughness, } K_{\mathrm{c}} \\
(\mathrm{MPa} \sqrt{\mathrm{m}})\end{array}$} & \multirow{2}{*}{$\begin{array}{c}K_{\max , \text { th }} \\
/ K_{\mathrm{c}}\end{array}$} & \multicolumn{2}{|c|}{$\begin{array}{c}\text { Paris Law } \\
d a / d N=C^{\prime} \Delta K^{m}\end{array}$} \\
\hline & & $\begin{array}{c}\Delta K_{\text {th }} \\
(\mathrm{MPa} \sqrt{\mathrm{m}})\end{array}$ & $\begin{array}{c}K_{\max , \text { th }} \\
(\mathrm{MPa} \sqrt{\mathrm{m}})\end{array}$ & & & $m$ & $C^{\prime}$ \\
\hline \multirow[t]{2}{*}{$3 \mathrm{ABC}$} & $25^{\circ}$ & 5.3 & 5.9 & 7.6 & 0.78 & 45 & $4.4 \times 10^{-41}$ \\
\hline & $1300^{\circ}$ & 3.5 & 3.9 & 4.5 & 0.87 & 44 & $4.3 \times 10^{-34}$ \\
\hline \multirow[t]{2}{*}{$5 \mathrm{ABC}$} & $25^{\circ}$ & 7.1 & 7.9 & 8.9 & 0.88 & 133 & $9.5 \times 10^{-124}$ \\
\hline & $1300^{\circ}$ & 6.1 & 6.8 & 7.4 & 0.92 & 107 & $3.7 \times 10^{-95}$ \\
\hline
\end{tabular}




\section{List of Figure Captions}

Fig. 1. SEM micrographs of etched surfaces of ABC-silicon carbides, showing the characteristic grain structures: (a) uniformly elongated grains in $3 \mathrm{ABC}$, (b) bimodal structure of elongated $(\alpha-\mathrm{SiC})$ and equiaxed $(\beta-\mathrm{SiC})$ in $5 \mathrm{ABC}$, and (c) equiaxed grains with sparsely distributed needle-like grains in 7ABC. (Courtesy of Q. Yang)

Fig. 2. High-resolution TEM micrographs showing the nature of the grain-boundary films in hot-pressed $\mathrm{SiC}$ with different $\mathrm{Al}$ content, showing (a) amorphous films in $3 \mathrm{ABC}$, (b) fully crystallized films in 7ABC, and (c) amorphous, (d) partially crystallized and (e) fully crystallized films in 5ABC. Fig. 3. Crack-growth resistance, $K_{\mathrm{R}}$, curves, plotted as a function of crack extension, $\Delta a$, for as-hot-pressed $\mathrm{xABC}-\mathrm{SiC}$ at room temperature.

Fig. 4. Cyclic fatigue-crack growth rates, $d a / d N$, at $R=0.1$ in $\mathrm{ABC}-\mathrm{SiC}$, as a function of the applied stress-intensity range, $\Delta K$, at temperatures of $25^{\circ}$ and $1300^{\circ} \mathrm{C}$. Note that $7 \mathrm{ABC}$ is sufficiently brittle that it exhibits no subcritical crack growth, i.e., it fails catastrophically once $K_{\max }>K_{\mathrm{c}}$; the dashed curve for this structure is drawn where $K_{\mathrm{th} \text {,max }}$ $=K_{\mathrm{c}}$.

Fig. 5. SEM micrographs of the overload fracture surfaces of (a) 3ABC-, (b) 5ABC- and (c) $7 \mathrm{ABC}-\mathrm{SiC}$. Fracture in $3 \mathrm{ABC}$ and $5 \mathrm{ABC}$ is intergranular, whereas it is predominantly transgranular in 7ABC.

Fig. 6. SEM micrographs of metallographic sections taken perpendicular to the fracture surface showing the crack paths during fatigue-crack growth at $25^{\circ} \mathrm{C}$ and $1300^{\circ} \mathrm{C}$ for $3 \mathrm{ABC}(\mathrm{a}, \mathrm{b})$ and $5 \mathrm{ABC}-\mathrm{SiC}(\mathrm{c}-\mathrm{f})$. Frictional bridging $(\mathrm{a}, \mathrm{b}, \mathrm{f})$ was most common in $3 \mathrm{ABC}$ while uncracked-ligament bridges $(\mathrm{c}, \mathrm{d}, \mathrm{e})$ were predominant in $5 \mathrm{ABC}$. The horizontal arrows indicate the general direction of crack growth.

Fig. 7. Transmission electron micrographs near the crack tip in (a) $3 \mathrm{ABC}$, and (b, c) $5 \mathrm{ABC}$ grown under cyclic loading at $1300^{\circ} \mathrm{C}(R=0.1, v=25 \mathrm{~Hz})$. Note in (b) the equiaxed grains also fracture intergranularly and in (c) a failure of uncracked ligament. Large arrows indicate the general direction of crack propagation, and small arrows point to the primary cracks near the crack tip.

Fig. 8. Comparison of the crack-opening profiles for a monotonically-loaded crack in the $3 \mathrm{ABC}$ and $5 \mathrm{ABC}$ microstructure after R-curve testing. Samples were loaded in situ in a field-emission FESEM to an applied driving force of $6.2 \mathrm{MPa} \sqrt{\mathrm{m}}$. The inset shows the curve fit for the first $70 \mu \mathrm{m}$ behind the crack tip, where the solid line is for $5 \mathrm{ABC}$ $\left(K_{\text {tip }}=1.6 \mathrm{MPa} \sqrt{\mathrm{m}}\right)$, and the broken line for $3 \mathrm{ABC}\left(K_{\mathrm{tip}}=2.5 \mathrm{MPa} \sqrt{\mathrm{m}}\right)$.

Fig. 9. Schematic illustrations of how the crack paths lead to the development (or not) of crack bridging in (a) 3ABC, (b) 5ABC, and (c) 7ABC-SiC. Note how the predominant mode of bridging in $3 \mathrm{ABC}$ is from frictional grain bridging, whereas it results more from uncracked ligaments in $5 \mathrm{ABC}$; in contrast, no bridging is developed in the 7ABC. 

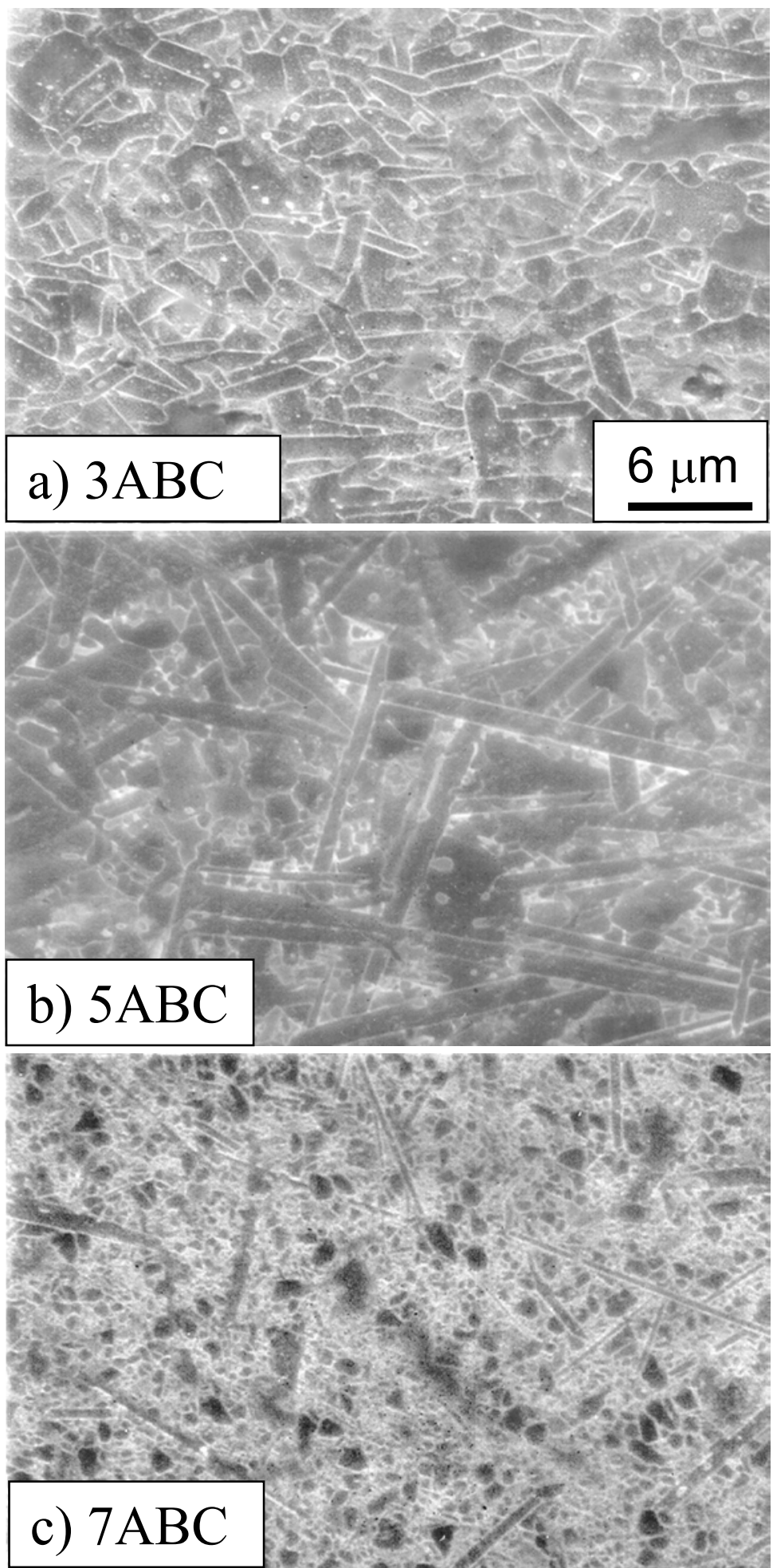

Fig. 1. SEM micrographs of etched surfaces of ABC-silicon carbides, showing the characteristic grain structures: (a) uniformly elongated grains in $3 \mathrm{ABC}$, (b) bimodal structure of elongated $(\alpha-\mathrm{SiC})$ and equiaxed $(\beta-\mathrm{SiC})$ in $5 \mathrm{ABC}$, and (c) equiaxed grains with sparsely distributed needle-like grains in 7ABC. (Courtesy of Q. Yang) 

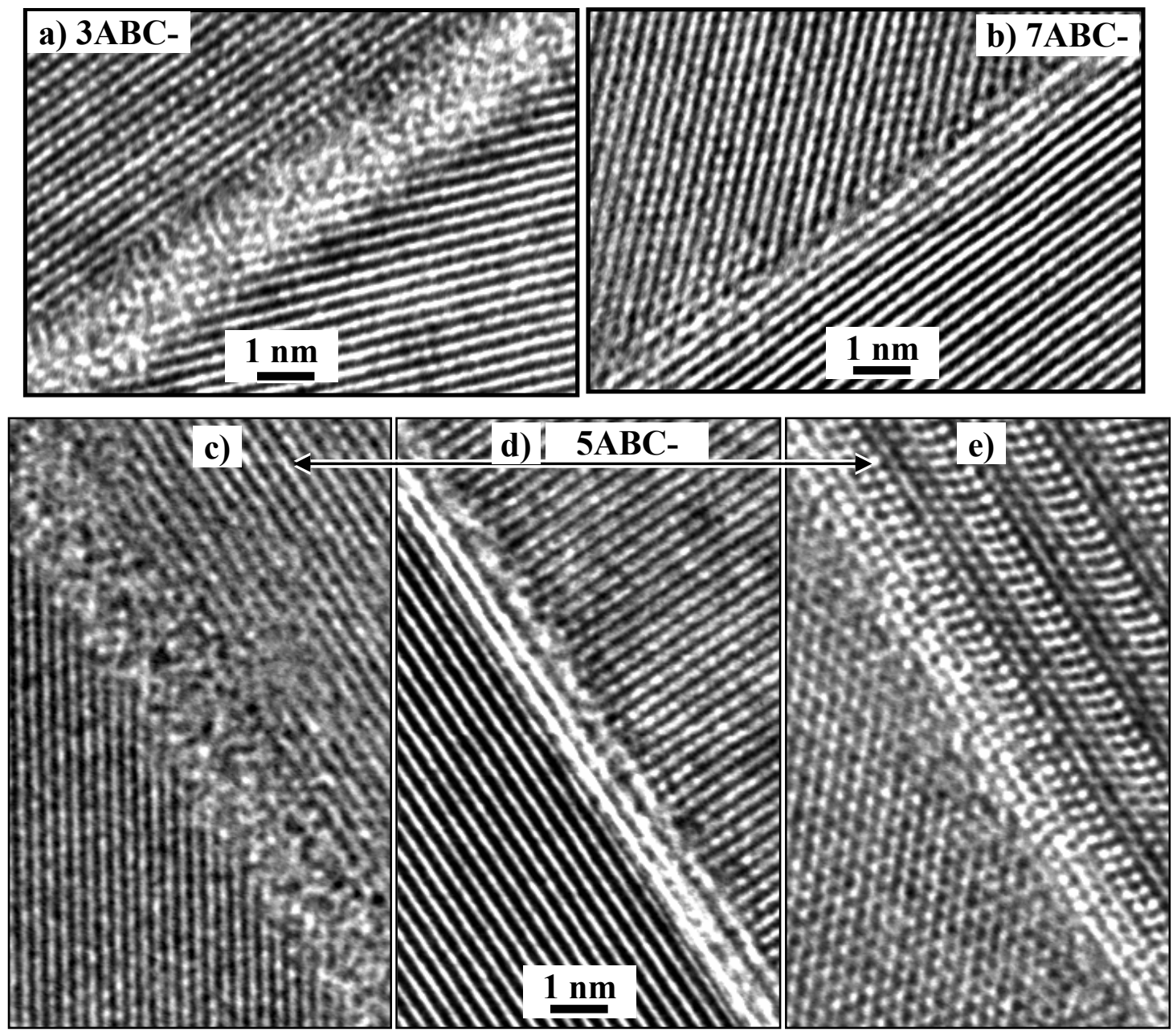

Fig. 2. High-resolution TEM micrographs showing the nature of the grain-boundary films in hot-pressed $\mathrm{SiC}$ with different $\mathrm{Al}$ content, showing (a) amorphous films in $3 \mathrm{ABC}$, (b) fully crystallized films in 7ABC, and (c) amorphous, (d) partially crystallized and (e) fully crystallized films in $5 \mathrm{ABC}$. 


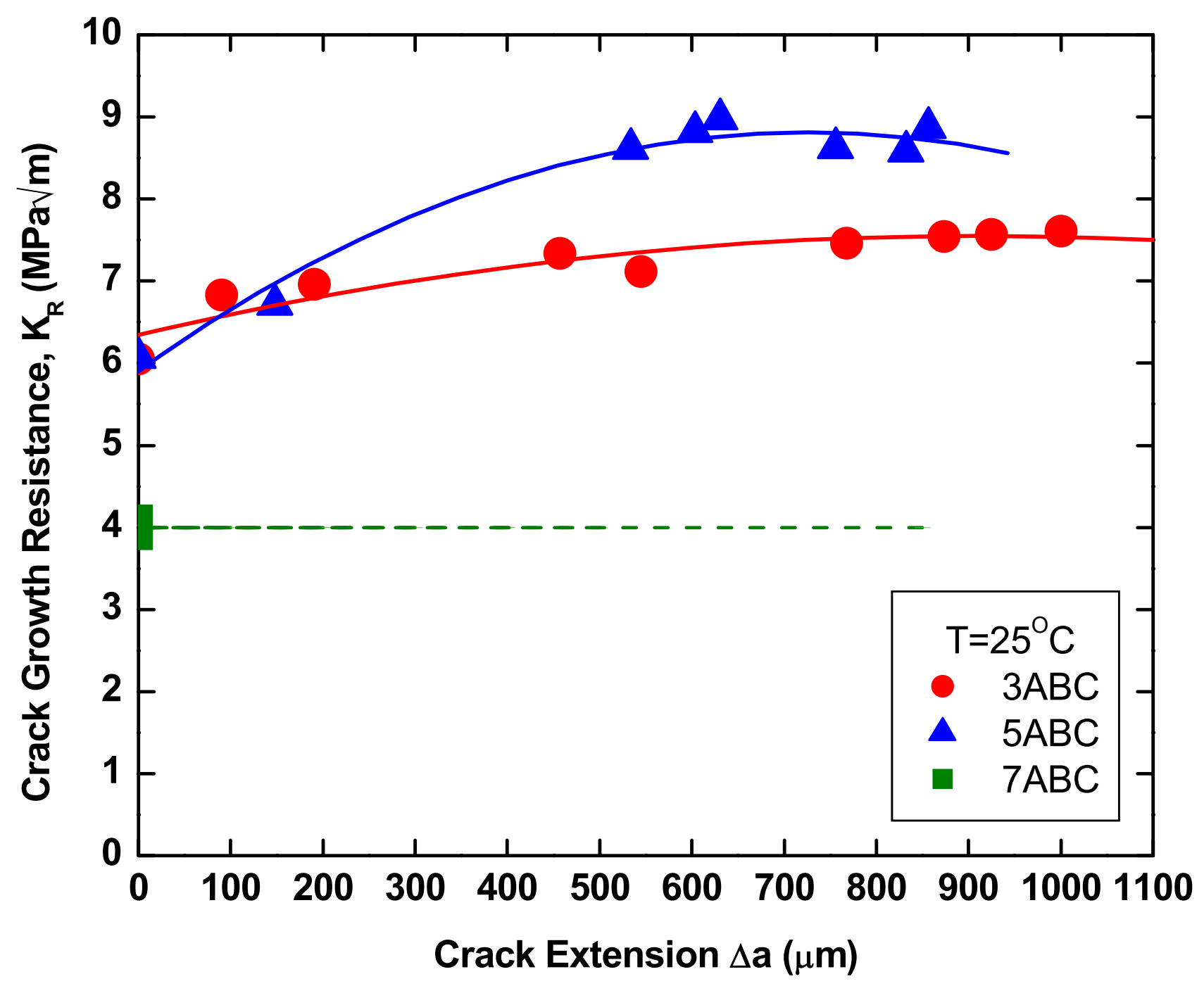

Fig. 3. Crack growth resistance, $K_{R}$, plotted as a function of crack extension, $\Delta a$, for ashot-pressed $\mathrm{xABC}-\mathrm{SiC}$ at room temperature. 


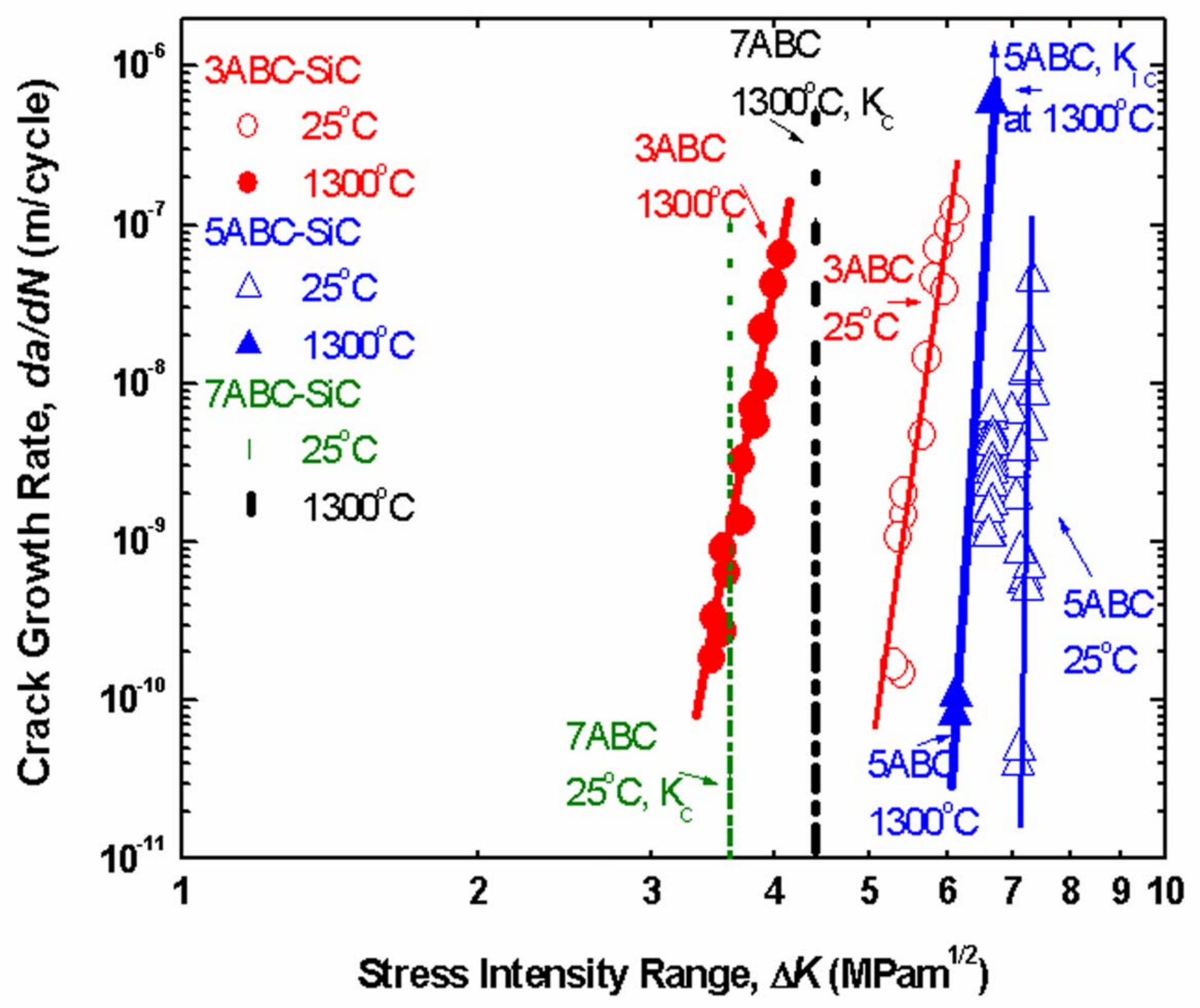

Fig. 4. Cyclic fatigue-crack growth rates, $d a / d N$, at $R=0.1 \mathrm{in} \mathrm{ABC}-\mathrm{SiC}$, as a function of the applied stress-intensity range, $\Delta K$, at temperatures of $25^{\circ}$ and $1300^{\circ} \mathrm{C}$. Note that $7 \mathrm{ABC}$ is sufficiently brittle that it exhibits no subcritical crack growth, i.e., it fails catastrophically once $K_{\max }>K_{\mathrm{c}}$; the dashed curve for this structure is drawn where $K_{\mathrm{th} \text {, max }}$ $=K_{\mathrm{c}}$. 


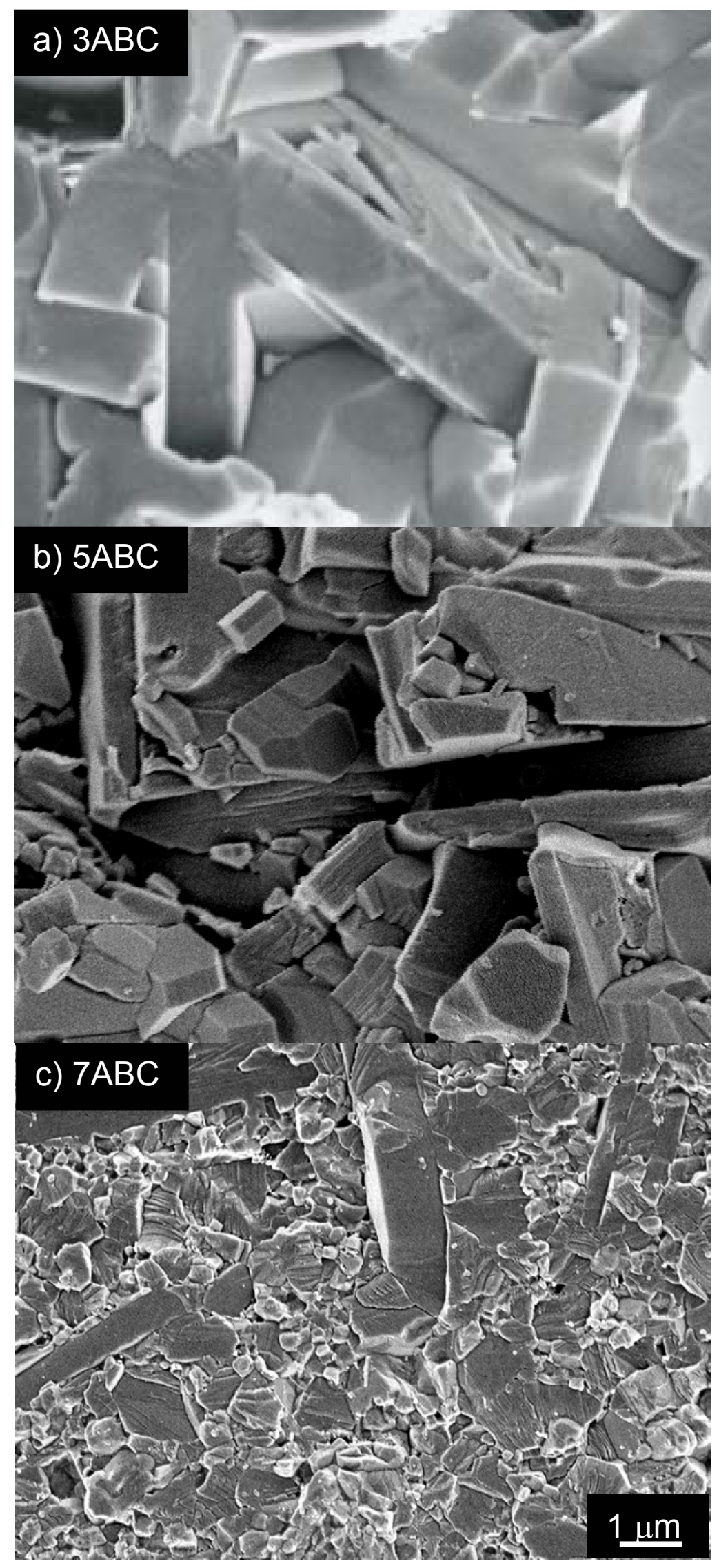

Fig. 5. SEM micrographs of the overload fracture surfaces of (a) 3ABC-, (b) 5ABC- and (c) $7 \mathrm{ABC}-\mathrm{SiC}$. Fracture in $3 \mathrm{ABC}$ and $5 \mathrm{ABC}$ is intergranular, whereas it is predominantly transgranular in $7 \mathrm{ABC}$. 

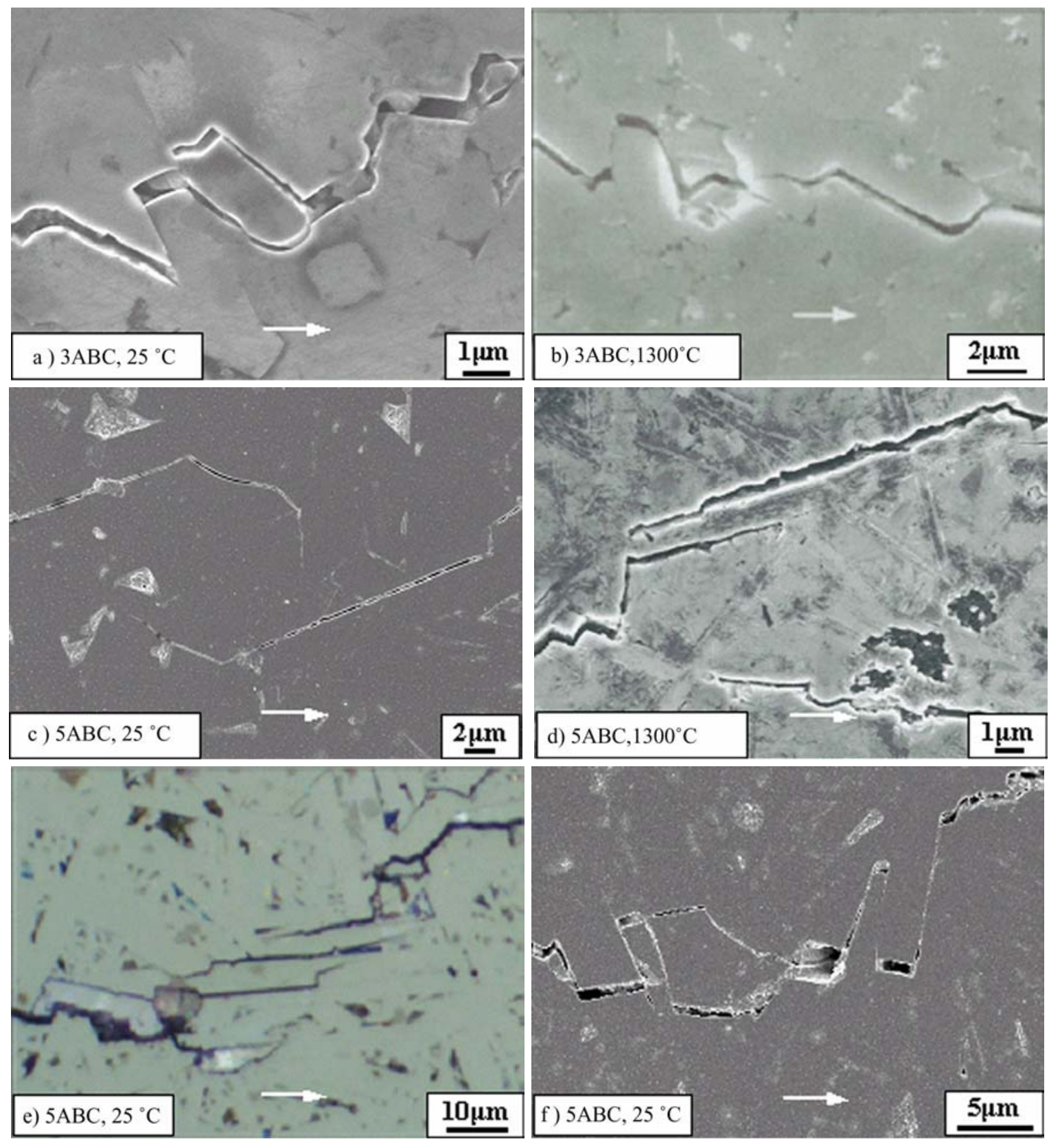

Fig. 6. SEM micrographs of metallographic sections taken perpendicular to the fracture surface showing the crack paths during fatigue-crack growth at $25^{\circ} \mathrm{C}$ and $1300^{\circ} \mathrm{C}$ for $3 \mathrm{ABC}(\mathrm{a}, \mathrm{b})$ and $5 \mathrm{ABC}-\mathrm{SiC}(\mathrm{c}-\mathrm{f})$. Frictional bridging $(\mathrm{a}, \mathrm{b}, \mathrm{f})$ was most common in $3 \mathrm{ABC}$ while uncracked ligament bridges $(\mathrm{c}, \mathrm{d}, \mathrm{e})$ were predominant in $5 \mathrm{ABC}$. The horizontal arrows indicate the general direction of crack growth. 

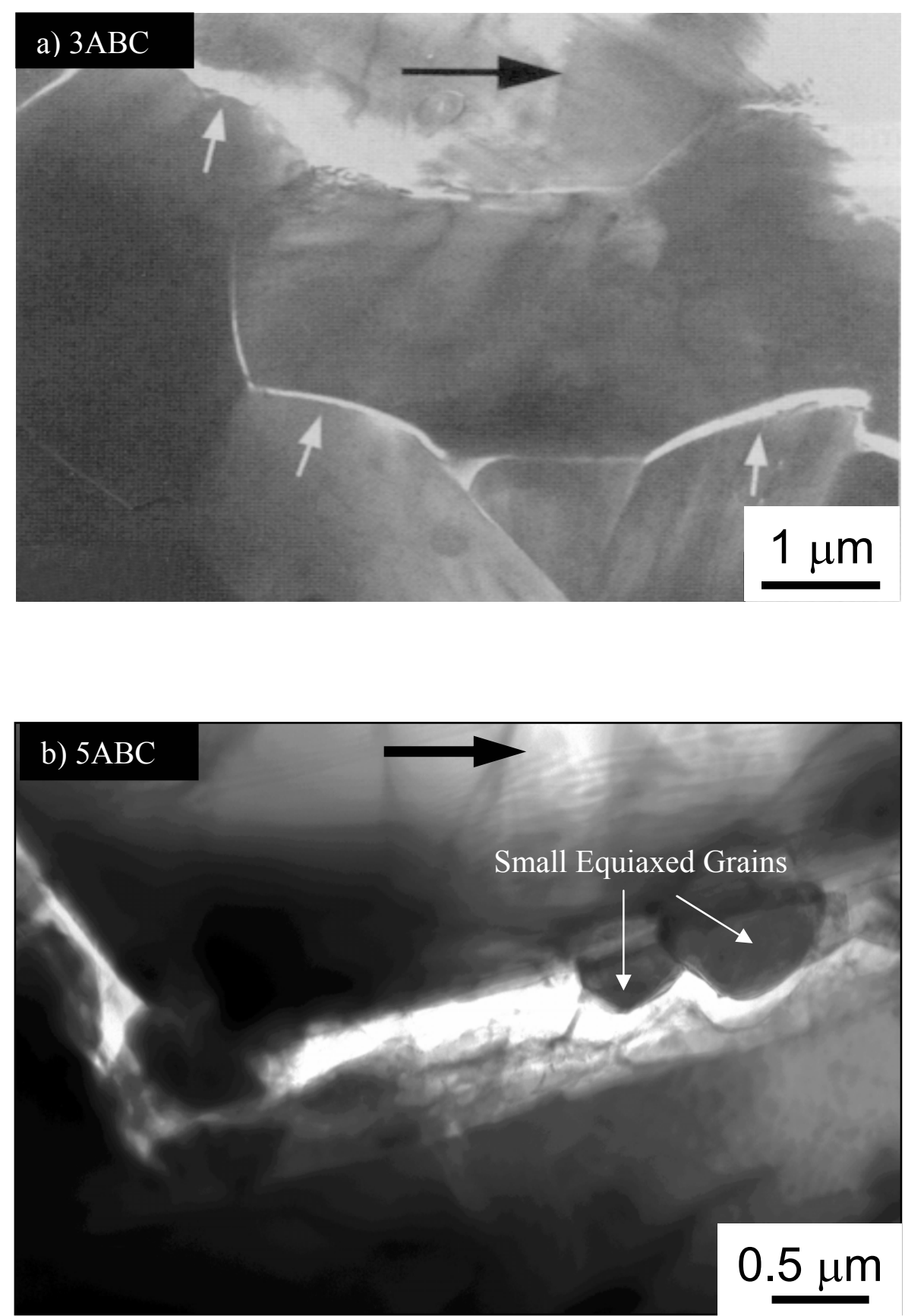


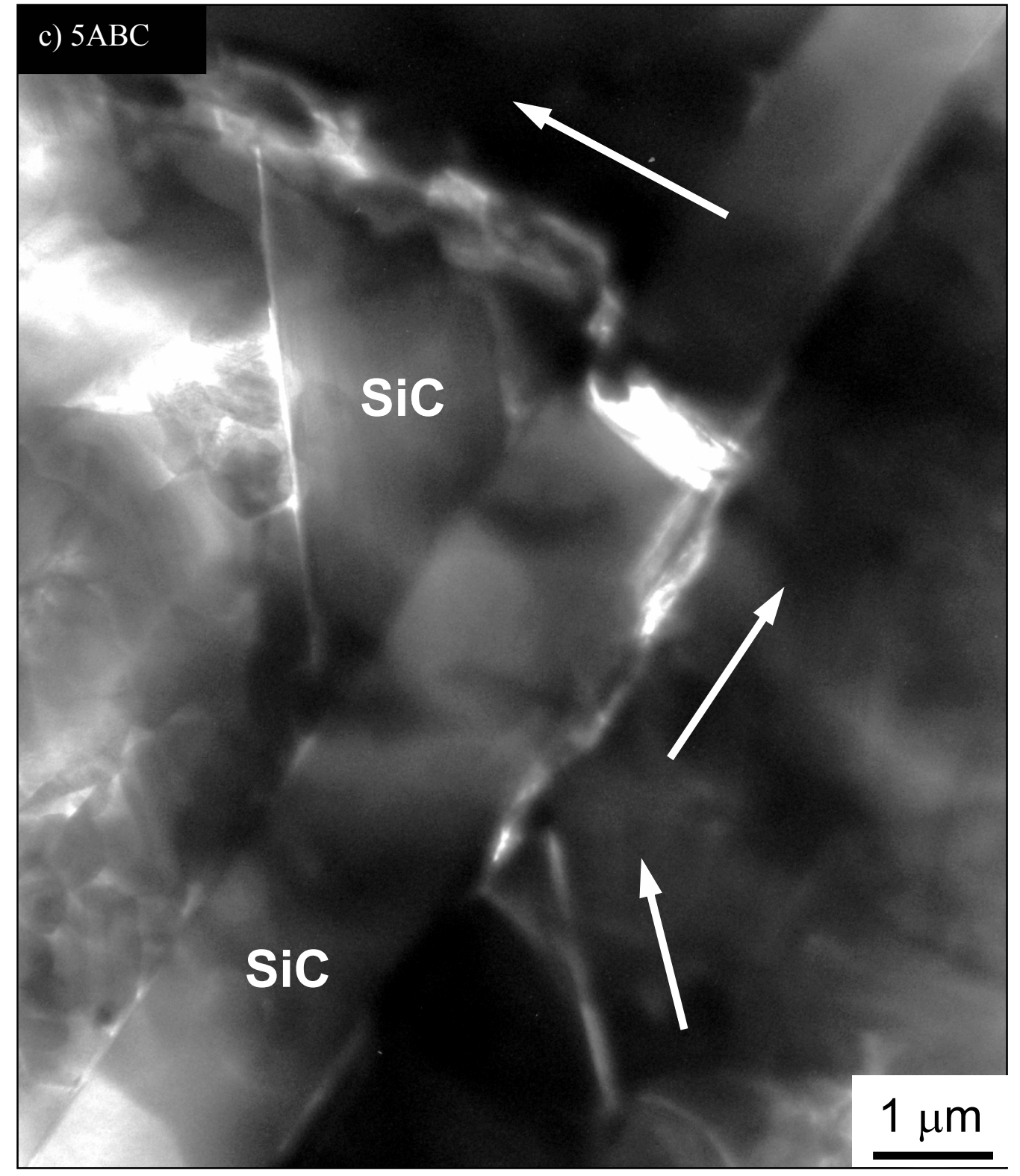

Fig. 7. Transmission electron micrographs near the crack tip in (a) $3 \mathrm{ABC}$, and (b, c) $5 \mathrm{ABC}$ grown under cyclic loading at $1300^{\circ} \mathrm{C}(R=0.1, v=25 \mathrm{~Hz})$. Note in (b) the equiaxed grains also fracture intergranularly and in (c) a failure of uncracked ligament. Large arrows indicate the general direction of crack propagation, and small arrows point to the primary cracks near the crack tip. 


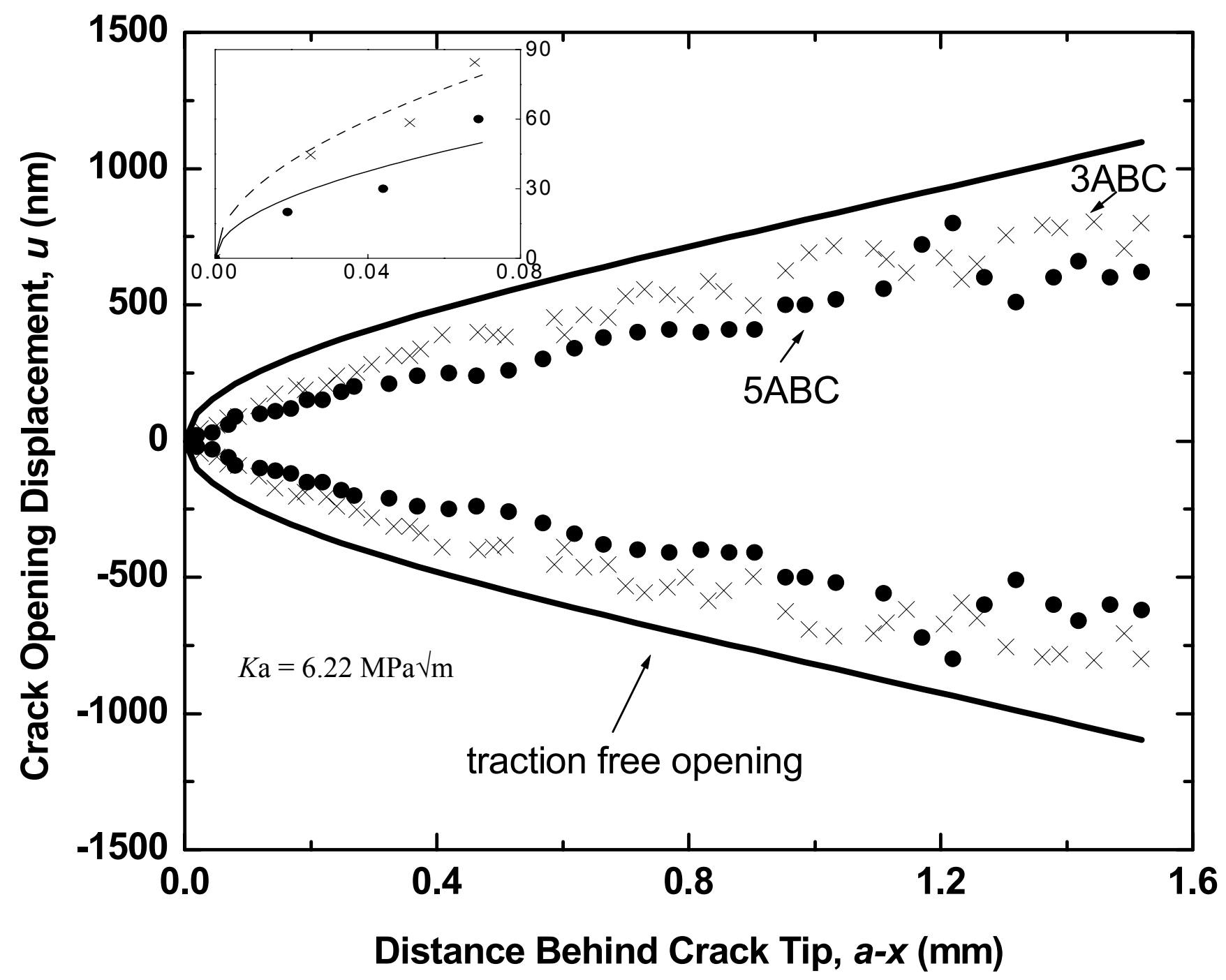

Fig. 8. Comparison of the crack-opening profiles for a monotonically-loaded crack in the $3 \mathrm{ABC}$ and $5 \mathrm{ABC}$ microstructure after R-curve testing. Samples were loaded in situ in a field-emission FESEM to an applied driving force of $6.2 \mathrm{MPa} \sqrt{\mathrm{m}}$. The inset shows the curve fit for the first $70 \mu \mathrm{m}$ behind the crack tip, where the solid line is for $5 \mathrm{ABC}$ $\left(K_{\text {tip }}=1.6 \mathrm{MPa} \sqrt{\mathrm{m}}\right)$, and the broken line for $3 \mathrm{ABC}\left(K_{\mathrm{tip}}=2.5 \mathrm{MPa} \sqrt{\mathrm{m}}\right)$. 


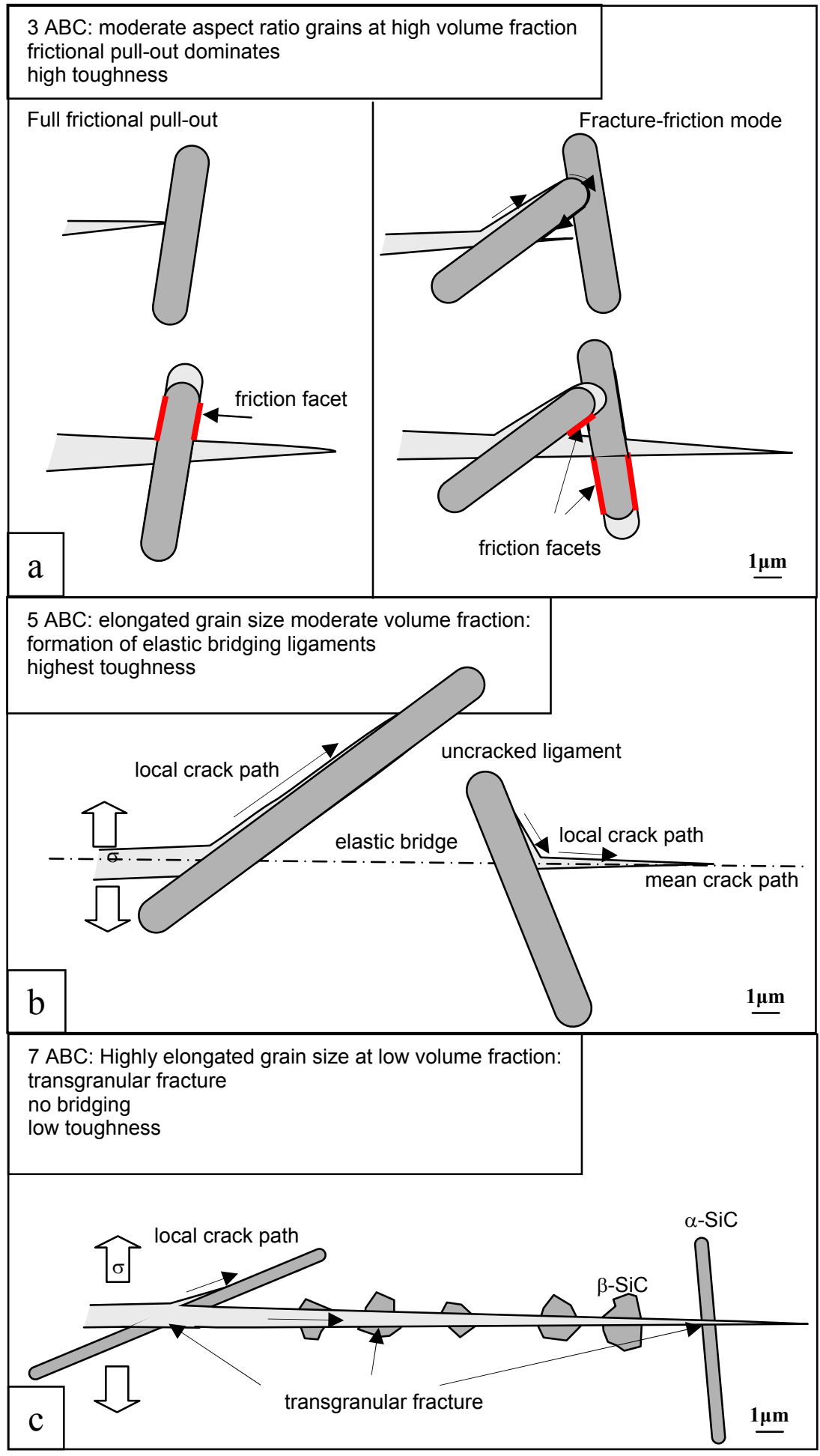

Fig. 9. Schematic illustrations of how the crack paths lead to the development (or not) of crack bridging in (a) 3ABC, (b) 5ABC, and (c) 7ABC-SiC. Note how the predominant mode of bridging in $3 \mathrm{ABC}$ is from frictional grain bridging, whereas it results more from uncracked ligaments in $5 \mathrm{ABC}$; in contrast, no bridging is developed in the 7ABC. 